\title{
Immunogenicity Specimen Assessments Group Identifier
}

National Cancer Institute

\section{Source}

National Cancer Institute. Immunogenicity Specimen Assessments Group Identifier. NCI

Thesaurus. Code C117552.

A character or string that represents an immunogenicity specimen assessments group. 